Best Available Evidence on Communicative First Aid Interventions by Laypeople for Preventing and Relieving Posttraumatic Stress Disorder-Related Symptomatology Following Traumatic Events

\author{
Niels De Brier ${ }^{1}$, Vere Borra ${ }^{1,2}$, Kim Dockx ${ }^{1}$, Hans Scheers ${ }^{1}$, Stijn Stroobants ${ }^{3}$, Emmy De \\ Buck $^{1,2,4}$, Karen Lauwers ${ }^{3}$, \& Philippe Vandekerckhove ${ }^{4,5}$ \\ ${ }^{1}$ Centre for Evidence-Based Practice, Belgian Red Cross, Mechelen, Belgium \\ ${ }^{2}$ Cochrane First Aid, Mechelen, Belgium \\ ${ }^{3}$ Humanitarian Services, Belgian Red Cross, Mechelen, Belgium \\ ${ }^{4}$ Department of Public Health and Primary Care, Faculty of Medicine, KU Leuven, Leuven, \\ Belgium \\ ${ }^{5}$ Belgian Red Cross, Mechelen, Belgium
}

\begin{abstract}
Author Note
We have no conflicts of interest relevant to the manuscript to declare. All authors are employees of the Belgian Red Cross and receive no other funding. One of the activities of the Belgian Red Cross is providing first aid training, including training related to mental health, to laypeople. This work was made possible through funding from the Foundation for Scientific Research of the Belgian Red Cross (Mechelen, Belgium) and the Flemish Ministry of Welfare, Public Health, and Family (Brussels, Belgium). The funding body did not influence the content of the manuscript.

We would like to thank Sarah Verlinden, Koen Van Praet (Psychosocial Intervention Service, Belgian Red Cross, Mechelen, Belgium), and Gorik Kaesemans (Zorgnet-Icuro, Brussels, Belgium) for their fruitful discussions as content experts.
\end{abstract}


Correspondence concerning this article should be sent to Niels De Brier, Centre for Evidence-Based Practice, Belgian Red Cross, Motstraat 42 Mechelen, Belgium. E-mail: niels.debrier@cebap.org 


\begin{abstract}
Trauma-exposed individuals are at risk of developing mental health problems, including posttraumatic stress disorder (PTSD). As an exposed individual's friend or family member may be the first person to provide posttrauma relief, informing and training laypeople in psychosocial first aid may benefit mental health outcomes of trauma-exposed individuals. We aimed to (a) collect the best available evidence on communication as a first-aid intervention in assisting individuals following traumatic events and (b) formulate practical recommendations. Systematic literature searches were conducted in three databases (March 2019). Following study selection, the extracted data were tabulated and synthesized narratively. The evidence was appraised according to the GRADE methodology and evaluated by a multidisciplinary expert panel to formulate recommendations for practice. Out of 1,724 articles, no experimental studies were identified, showing a complete lack of high-quality controlled studies on the efficacy of communicative practices. However, when lower-quality study designs were included, nine cross-sectional studies constituted the best available evidence. The studies suggested that positive communication by family members, $r=-.38$, aOR $=0.26$, $\beta=-.22, p<.001-p<.05$, and expressive coping by the victim, $\beta=-.62, p<.001$, were associated with PTSD diagnosis and/or symptom severity; however, the evidence was of very low certainty. The expert panel took the methodological limitations into account when formulating weak practical recommendations. Cross-sectional studies currently provide the best possible evidence for developing guidelines on psychosocial first aid. High-quality controlled studies are needed to establish casual associations and identify the most effective interventions.
\end{abstract}




\section{Best Available Evidence on Communicative First Aid Interventions by Laypeople for Preventing and Relieving Posttraumatic Stress Disorder-Related Symptomatology Following Traumatic Events}

A traumatic event involves exposure to actual or threatened death, serious injury, or sexual violence evoking strong sensory experiences (Benjet et al., 2016; Bryant, 2019). Unfortunately, about $70 \%$ of individuals worldwide experience or witness at least one traumatic event during their lifetime, most frequently accidents and/or injuries, but also natural disasters, terroristic attacks, sexual abuse, or violence (Benjet et al., 2016; Liu et al., 2017). Posttraumatic stress symptoms are common after exposure to a traumatic event, but only 4\% of trauma-exposed individuals develop posttraumatic stress disorder (PTSD; Kessler et al. 2017; Liu et al. 2017), the most common posttraumatic psychological disorder. According to the PTSD diagnostic criteria in the fifth edition of the Diagnostic and Statistical Manual of Mental Disorders (5th ed.; American Psychiatric Association [APA], 2013), there are four symptom clusters that the victim should manifest: (i) intrusive thoughts about the event, such as flashbacks and nightmares; (b) avoidance; (c) negative thoughts or feelings that began or are worsened after the event; and (d) trauma-related arousal and reactivity, such as irritability or reckless behavior. Several factors influence whether individuals develop PTSD following a traumatic event, including victim-specific factors, such as psychiatric history, and the type of traumatic to which the individual was exposed, with physical or sexual violence typically leading to higher rates of PTSD compared with experiences such as automobile accidents (Kessler et al., 2017; Liu et al., 2017; Yehuda \& LeDoux, 2007).

It is currently unclear whether early interventions provided by professionals are associated with beneficial mental health outcomes following a traumatic event. For example, several systematic reviews have found no effect or even a harmful effect of immediate 
psychological debriefing following traumatic experiences with relation to PTSD symptoms (Arendt \& Elklit, 2001; Rose et al., 2002, 2003; Van Emmerik et al., 2002).

Interventions that incorporate the provisions of basic comfort, information, effective communication, psychosocial support, and attendance to immediate practical and emotional needs of the affected individuals are more general in nature and can help victims recover from early stress reactions (Brewin et al., 2000; Brymer et al., 2012). These supportive interventions can be performed by laypeople on or near the site of the traumatic event, but they do not necessarily involve a discussion of the event itself (Schafer et al., 2010). Recommendations for crisis intervention programs have already taken into account that the ability to rely on good social support networks can have a beneficial impact on recovery, hypothesizing that appropriate early psychosocial support from laypeople, whether friends, family members, coworkers, or volunteers, may help prevent the development of PTSD or minimize its severity (Brewin et al., 2000; Litz et al., 2002; McNally et al., 2003). One intervention strategy that includes psychosocial support is psychological first aid, which is directed at assisting individuals to cope with the experience and consequences of a disaster (Dieltjens et al., 2014). However, systematic evaluations on the effectiveness of psychological first aid practices have shown that the currently available scientific literature does not provide any evidence regarding the effectiveness of psychological first aid interventions in helping disaster victims (Dieltjens et al., 2014; Fox et al., 2012). Of note, these systematic literature searches have only reviewed the evidence in existing guidelines, systematic reviews, and individual studies that have had a controlled experimental or observational design (Dieltjens et al., 2014; Fox et al., 2012). As such, there is a need to also review the body of evidence on psychosocial first aid interventions in uncontrolled studies with a cross-sectional approach. Improving knowledge and skills in laypeople and first responders about ways to prevent, recognize, and respond to trauma-related psychological distress could provide 
important benefits for mental health outcomes in individuals exposed to these events. To date, the available manuals on mental health first aid have typically been based on expert opinion, and no systematic literature searches have been conducted (Kitchener et al., 2015).

The present study examined communicative first aid provided to children or adults exhibiting PTSD-related symptoms following traumatic event exposure. As a friend, family member, or other layperson may be the first individual to provide relief in the aftermath of a traumatic event, the low-threshold communications described herein were aimed at laypeople and involved supportive actions or coping strategies and did not necessarily involve the discussion of the traumatic event. Against this background, the objective of the present literature search was to systematically assess the effectiveness of communication provided by laypeople as a psychosocial first aid intervention aimed at reducing psychological distress and preventing the development of PTSD in the aftermath of a traumatic event.

\section{Method}

\section{Development of the Population, Intervention, Comparison, Outcome (PICO) Question}

Currently available programs on first aid following traumatic events describe a supportive response to an individual who has experienced a traumatic event and generally involve the following themes: approach the person; provide practical care and assistance; listen nonjudgmentally; help the individual connect to information, services, and social supports; and encourage the individual to get appropriate professional help (Brymer et al., 2012; Morgan et al., 2018; World Health Organization, 2011). For the present study, these different actions were dissected and evaluated by content experts, who judged that approaching and listening are related to communication, defined herein as any verbal intervention that is feasible for a layperson, such as engaging conversation, talking with the individual, providing comforting nonverbal communication, using motivational interviewing techniques, or any other form of communication that is used as a coping strategy by the 
victims themselves. In this context, the present review was aimed at the general public (i.e., individuals without any medical, paramedical, or psychological background; herein referred to as "laypeople”), and the following PICO question was formulated: "In persons who have experienced a traumatic event (P), are different forms of communication by laypeople (I) effective for improving mental health outcomes, including prevention of PTSD development and reduction of PTSD symptom severity (O), as compared with no communication (C)?”

\section{Procedure}

This systematic literature search was performed as part of the development of guidelines on first aid for mental health problems in a Western European context (Dockx et al., 2020) according to our methodological charter (De Buck et al., 2014). Furthermore, the search has been reported in accordance with the Preferred Reporting Items for Systematic Reviews and Meta-Analyses (PRISMA) checklist (Moher et al., 2009; see Supplementary Materials). No protocol for the systematic literature searches was registered beforehand due to time constraints, as the Flemish Government demanded to finalize and publish the evidencebased guideline in 2019.

\section{Inclusion and Exclusion Criteria}

Studies were eligible if they addressed the PICO question, were published in English or Dutch from the time of inception of the databases until March 2019 and met the following inclusion and exclusion criteria.

\section{Population}

Included studies comprised samples of children or adults who had been exposed to a traumatic event or multiple events, such as traffic or occupational accidents that involved experiencing or witnessing actual or threatened death or having experienced a serious injury, interpersonal violence, or physical and/or sexual abuse. Studies were excluded if their samples comprised individuals who had been exposed to war-related traumatic events or 
patients who had been diagnosed with life-limiting diseases, such as terminal cancer, or those who had experienced medical incidents involving natural causes, such as heart attacks. First aid assistance in the immediate aftermath of war-related events was given a low priority for developing evidence-based guidelines adapted to a Western European context due to time constraints. Nonimmediate life-threatening illness or medical incidents involving natural causes were excluded as they do not meet PTSD Criterion A in the fifth edition of the Diagnostic and Statistical Manual of Mental Disorders (DSM-5).

\section{Interventions}

Studies were included if their interventions comprised communication strategies that could be performed by a layperson administering first aid, including family members, friends, colleagues, caregivers, pastoral workers, or the victim themselves (self-help). Included studies mentioned that communication took place when the receiver experienced posttraumatic symptoms or when it was used as a coping strategy. Relevant interventions were discussed with content experts. Studies were excluded if they discussed interventions with no focus on the communication effect (e.g., family/peer relations, social support, loneliness, secretkeeping) related to disclosure of illness or diagnosis or if they involved multiple interventions that did not allow us to extract the effect of communication itself or were based on massmedia campaigns and/or internet support groups. Communication interventions that were performed by mental health professionals (i.e., psychologists or psychiatrists) and could not feasibly be performed by a layperson, such as psychological debriefing, professional counseling, eye movement desensitization and reprocessing, family-focused therapy, couples therapy, group therapy, cognitive stimulation, cognitive behavioral therapy, and health education were also excluded. 


\section{Outcomes}

Included studies reported on mental health outcomes that could be directly linked to the experienced traumatic event (i.e., PTSD-related symptomatology and/or diagnosis). Studies were excluded if the reported outcomes were potentially related but less directly linkable mental health problems, such as depression, anxiety, eating disorders, alcohol and/or substance abuse, suicidality, disturbed sleeping behavior, bipolar disorder, or schizophrenia.

\section{Study Design}

Included studies comprised (a) systematic reviews (as source of studies), if the search strategy and selection criteria were clearly described and if at least MEDLINE and Embase were searched; (b) experimental studies, including randomized controlled trials, quasi- or non-randomized controlled trials, controlled before-and-after studies, and controlled interrupted time series; and (c) observational studies, including cohort and case-control studies, controlled before-and-after studies, controlled interrupted time series, and crosssectional studies. Studies were excluded if they were case series, qualitative studies, conference abstracts, preprints, doctoral theses, animal studies, ex vivo or in vitro studies, or studies that reported no quantitative data. The authors of potentially eligible study protocols or registered clinical trials were not contacted about unpublished data due to time constraints.

\section{Search Strategy and Study Selection}

All searches were performed on March 8, 2019, within the following databases: PsycINFO (via the APA PsycNET database), MEDLINE (via the PubMed interface), and Embase (via the Embase.com interface). For each database, two review authors developed the search strategy using both index and free-text terms; this was then reviewed by a third author. The full search strategies for all databases are listed in the Supplementary Materials.

The subsequent study selection took place in two phases. Initially, two reviewers scanned the titles and abstracts identified by the search for relevance to the PICO question. 
Next, full texts were obtained to assess whether the studies met the selection criteria. The results from this selection phase were compared to ensure that all relevant studies had been identified. The level of agreement between the two reviewers was assessed using Cohen's kappa. Disagreements were resolved by discussion or by a third author. Finally, the two reviewers assessed the references and first 20 articles identified in the "similar articles" queue in MEDLINE (via the PubMed interface) from each included study regarding their relevance to the PICO question. Two rounds of systematic snowballing on reference lists and similar articles were performed.

\section{Data Extraction and Analysis}

Data concerning study design; population; risk factors; outcome measures; effect sizes, expressed as correlation coefficients $(r)$, regression coefficients $(\beta)$, or adjusted odds ratios $(\mathrm{aOR})$; and study quality were collected and tabulated by three reviewers. Review Manager (Version 5.3) was used to calculate the $95 \%$ confidence interval and $p$ values if they were not reported in the study and raw data were available. A $p$ value of less than .05 was considered statistically significant.

\section{Assessment of Certainty of Evidence}

Overall certainty of the evidence was evaluated according to the Grading of Recommendations Assessment, Development, and Evaluation (GRADE) methodology (Guyatt et al., 2008). This approach uses the following criteria to determine the certainty of the evidence for systematic reviews: (a) risk of bias (i.e., the methodological quality of the studies), (b) inconsistency (i.e., unexplained heterogeneity of results across studies), (c) imprecision (i.e., when studies include relatively few participants and few events and, thus, have wide confidence intervals around the estimate of the effect), (d) indirectness (i.e., evidence from an indirect population, intervention, comparator, or outcome- the question being addressed is different from the available evidence regarding the population, 
intervention, comparator, or an outcome), and (e) publication bias (i.e., systematic underestimate or an overestimate of the underlying beneficial or harmful effect due to the selective publication of studies). The risk of bias for each individual observational study was analyzed by evaluating the eligibility criteria (i.e., participants in all exposure levels and with all outcomes are representative of the target population), methods for exposure and outcome variables (i.e., accurate and objective measurement of exposure and outcome variables), confounding factors (i.e., appropriate analysis methods or study designs that controlled for confounding domains were used), and loss to follow-up (Guyatt et al., 2011). The initial certainty of the evidence of observational studies was graded as low and could be further downgraded for each of the previous certainty criteria to a very low level of evidence (Guyatt et al., 2008).

\section{Multidisciplinary Expert Meeting}

An expert panel consisting of 10 content experts (i.e., psychologists and psychiatrists who were active in mental health care and/or academia) and six mental health peer workers in training (i.e., individuals who had experience in receiving mental health care in the past and who were in the final stages of a specific trajectory embedded in social work education) from Flanders (Belgium) critically interpreted the best available evidence and formulated practical recommendations or “good practice points” (GPPs) during five meetings (Dockx et al., 2020). Based on the certainty of the best available evidence, the intervention feasibility and cost, and the potential benefits or adverse events of the intervention, the panel of experts decided on the strength of the practical recommendation (i.e., weak or strong). The GPPs were inter alia formulated when there was no scientific evidence available on the topic or when the intervention was considered to be common sense. 


\section{Results}

\section{Study Identification}

A flowchart of the identification and selection of studies is provided in Figure 1. In total, 2,370 articles were identified using the search strategy outlined in the Supplementary Materials. Once duplicates were removed, 1,724 articles were screened by title and abstract for their relevance to the PICO question. After title and abstract screening, two reviewers assessed the full text of 231. After the full-text evaluation, the level of agreement between the two reviewers was reflected by a Cohen's kappa of .56, which represents a moderate agreement. After resolving disagreement, 190 studies were excluded based on the intervention, 17 studies were excluded due to study design, three due to population, two due to language, and one due to the outcome. Furthermore, we excluded nine studies that had been published as abstracts only, and the full text of another study was unavailable. Most of the studies were excluded because they did not elaborate on the specific association between communication and PTSD diagnosis and/or symptomatology in the aftermath of a traumatic event but rather focused on elucidating the role of social support as a risk factor, which was too broad according to our selection criteria. At this stage, eight observational studies were included. Finally, we included one additional observational study after screening the reference lists of included studies as well as similar articles in PubMed, leading to a total of nine included studies.

\section{Characteristics of the Included Studies}

An overview of the characteristics of the included studies is shown in Table 1. All studies were observational cross-sectional studies. The role of communication was evaluated in different trauma populations, including individuals who had experienced sexual assault (Arata, 1999; DiMauro \& Renshaw, 2019), intimate partner violence (Machisa et al., 2018), terroristic attacks (Njenga et al., 2004; Tucker et al., 2000), child maltreatment (Milot et al., 
2010), kidnapping (Navia \& Ossa, 2003), and road traffic (Khodadadi-Hassankiadeh et al., 2017) and occupational accidents (Elklit, 1997). The participants in all included studies were exposed to a traumatic event and met the strict inclusion criteria. All studies used a questionnaire dealing with a list of potential risk factors for PTSD caseness and/or posttraumatic symptom severity (Arata, 1999; DiMauro \& Renshaw, 2019; Elklit, 1997; Khodadadi-Hassankiadeh et al., 2017; Machisa et al., 2018; Milot et al., 2010; Navia \& Ossa, 2003; Njenga et al., 2004; Tucker et al., 2000). All outcome measures were directly related to the traumatic event. Three studies evaluated whether talking to someone as a coping strategy was associated with a reduced risk of PTSD development or reduced symptom severity (Machisa et al., 2018; Njenga et al., 2004; Tucker et al., 2000), whereas four other studies evaluated the association between supportive communication and PTSD caseness and/or symptomatology (DiMauro \& Renshaw, 2019; Khodadadi-Hassankiadeh et al., 2017; Milot et al., 2010; Navia \& Ossa, 2003). In the latter studies, supportive communication was provided by family members (DiMauro \& Renshaw, 2019; Khodadadi-Hassankiadeh et al., 2017; Milot et al., 2010; Navia \& Ossa, 2003). The studies by Machisa et al. (2018), Njenga et al. (2004), and Tucker et al. (2000) highlighted the role of talking to friends, family, or someone else without specifying the communication interactions. Two other studies dealt with communication-based coping strategies related to expression and discussion of personal feelings (Arata, 1999; Elklit, 1997). All studies dealt with any verbal intervention performed by a layperson (i.e., family members, friends, or the individual themselves), such as positive communication, communicating with family members, or expressive coping. According to the selection criteria, these studies mentioned that communication or talking was done as a means of providing support in the aftermath of a traumatic event or was used as a coping strategy. 


\section{Synthesis of the Findings from the Included Studies}

A structured synthesis of the findings from the included studies can be found in Table

2. Overall, communication was shown to have a significant association with trauma-related outcomes across the studies, especially when exploring the different associations between positive communication in a family context and negative communication. Positive communication between family members, $r=-.38$, aOR $=0.26, \beta=-.22, p<.001-p<.05$, was significantly correlated with a reduced risk of PTSD development or reduced symptom severity (DiMauro \& Renshaw, 2019; Khodadadi-Hassankiadeh et al., 2017; Milot et al., 2010). Positive communication was defined by DiMauro and Renshaw (2019) as mutual discussion, expression, and negotiation between spouses. Milot et al. (2010) described aspects of positive mother-child affective communication to include an appropriate mother-child role and calm, comfortable interaction that flows smoothly toward mutually defined goals. Clear verbal and nonverbal exchanges and balanced and shared expression of both positive and negative affective states should occur within a generally positive mood and sustained warmth. Overall, high-quality affective communication is responsive and harmonious and not indifferent or conflictual (Milot et al., 2010). Good family communication was not further detailed by Khodadadi-Hassankiadeh et al. (2017). On the contrary, negative communication (i.e., a demand/withdrawal pattern between spouses in which one partner attempts to discuss a problem while the other avoids or ends the discussion) showed a significant association with increased PTSD symptom severity, $r=.28, p<.01$ (DiMauro \& Renshaw, 2019). With regard to kidnapping (Navia \& Ossa, 2003), there was no statistically significant association between family communication and PTSD symptom severity during captivity, $r=.31, p>.05$, or after release, $r=.20, p>.05$.

Several coping strategies have been identified and investigated as potential risk factors for developing PTSD in the aftermath of a traumatic event. Herein, we focus on coping 
strategies involving communication. Talking as a coping strategy from the viewpoint of the victim exhibited ambiguous effects. Studies by Tucker et al. (2000), Njenga et al. (2004), and Machisa et al. (2018) investigated whether trauma-exposed individuals benefited from talking to others about the traumatic event. Njenga et al. (2004) reported that talking about a terroristic attack, but not to a friend or co-worker, negatively impacted PTSD prevalence among victims of the attack, $p<.01$, whereas Tucker et al. (2000) reported no significant association between the risk factor "talking with friends and family helped" and PTSD severity, $r=-.15, p=.175$. Moreover, Machisa et al. (2018) could also not demonstrate a significant association between talking to someone else about intermediate partner violence, $a O R=1.29,95 \% \mathrm{CI}[0.59,2.80], p=.508$, and PTSD resilience

Other communicative coping strategies involve factors related to expression and discussion of personal feelings. On one hand, regression analyses showed that expressive coping, including (a) expressing feelings around others and (b) talking about one's feelings, was negatively associated with posttraumatic symptom severity, $\beta=-.62$, 95\%CI [-.94, -..31], $p<.001$ (Arata, 1999). On the other hand, social-emotional coping was significantly and positively correlated, $r=.50, p<.005$, with PTSD symptom severity (Elklit, 1997). In this case, the evaluation of social-emotional coping included the following statements based on the COPE checklist: "I discuss my feelings with someone," "I try to get emotional support from friends or relatives," "I get sympathy and understanding from someone,” and "I talk to someone about how I feel” (Carver, 2013).

\section{Study Quality and Certainty of Evidence}

An overview of the limitations in the study design for each included study is provided in the Supplementary Materials. The nine included studies were observational in nature, leading to a low initial certainty level. The certainty of the evidence was downgraded (i.e., -1) for limitations in study design (Supplementary Materials). All but three studies used an 
appropriate sampling strategy. Tucker et al. (2000) only included victims who sought help after the traumatic event, and individuals who did not receive services during the study period, for various reasons, were omitted from the analysis. Similarly, Njenga et al. (2004) recruited individuals who might have been seeking mental health support either at a clinic or at their workplace. Furthermore, Khodadadi-Hassankiadeh et al. (2017) only recruited victims of road traffic accidents in a hospital and, by doing so, excluded victims who did not make it to the hospital. All studies had a cross-sectional design, implying that the methods for measuring exposure and outcome variables were inappropriate, as they were measured at the same time via questionnaires. Furthermore, five studies did not correct for confounding factors and only reported univariate correlations (DiMauro \& Renshaw, 2019; Elklit, 1997; Navia \& Ossa, 2003; Njenga et al., 2004; Tucker et al., 2000). Of note, only the studies by Machisa et al. (2018) and Khodadadi-Hassankiadeh et al. (2017) took the use of previous medical of psychosocial services into account as a confounding factor in multivariate regression analyses when statistically significant in the univariate analyses. In addition, Navia and Ossa's (2003) analyses included not only kidnapping victims but also their family members, and the results for kidnapped individuals versus their family could not be distinguished. In the study by Milot et al. (2010), which dealt with preschool children, PTSD symptoms were evaluated based on input by the children's mothers and preschool teachers via questionnaire, thus potentially introducing bias in the outcome measures. Finally, Njenga et al. (2004) only reported on the level of significance (i.e., $p$ values), and correlations coefficients were lacking. The overall certainty of evidence was further downgraded because of imprecision (i.e., -1) due to limited sample sizes, large variability of the results, and/or a lack of data. There was no need to downgrade due to indirectness, inconsistency, or the risk of publication bias. In conclusion, we found a very low certainty evidence for the observational 
studies concerning first-aid communication measures in the aftermath of traumatic events, meaning that any estimate of effect is very uncertain.

\section{Translating the Best-Available Evidence Into Practical Recommendations}

The scientific evidence was presented to a multidisciplinary expert panel, which took into account that only low-certainty evidence was available and no causal associations could be inferred from the evidence. However, the associations suggested by the best-available evidence were in line with what the panel saw as "good practice.” Based on the limited evidence that positive communication in a family context and expressive coping are associated with improved mental health status, along with input from the experts and target population, the aims of the psychosocial first aid guidelines of the Belgian Red Cross following a potentially traumatic event are to (a) engage in conversation with the individual who experienced the traumatic event; (b) listen to what is on their mind and give the individual the opportunity to talk about the experience if they wish but never force them to talk; (c) offer empathic support, allowing them to express their thoughts and feelings; and (d) remain open to listen and talk about the event or other subjects at later time points. Further practical recommendations were formulated as GPPs, which were validated or newly formulated by the multidisciplinary expert panel (Dockx et al., 2020).

\section{Discussion}

The aim of this evidence-based analysis was to assess the association between communication strategies as a first-aid intervention and mental health outcomes, including the prevention of PTSD development and a reduction of PTSD symptom severity following potentially traumatic events. Out of 1,724 references screened, nine cross-sectional studies that used questionnaires were selected. By design, cross-sectional studies assess the intervention and outcome measures at the same time. As a consequence, no causal associations can be inferred from the present results. There was limited evidence that positive 
communication in a family context and expressive coping were associated with a reduced risk of developing PTSD or a reduction of PTSD symptom severity in individuals who experienced a traumatic event. In all included studies, communication was provided by family members, friends, or the trauma-exposed individual themselves (i.e., self-help). Although the certainty of the evidence can be considered to be very low based on study type (i.e., observational studies), risk of bias, and the imprecision of the results, the evidence shows that (trained) laypeople may have a role to play in first aid care of victims following traumatic events.

Our analysis was the first of which we are aware that attempted to collect evidence on communication as a first-aid intervention in the aftermath of a traumatic event. Previous efforts by Fox et al. (2012) and Dieltjens et al. (2014) examined psychological first aid more generally and could not identify any controlled studies to provide scientific evidence for psychological first aid in the aftermath of a disaster. Conducting research activities during the aftermath of a traumatic event is generally difficult, as the timing and context are unpredictable and these activities may hamper efforts to provide critical assistance to victims in need. Although cross-sectional studies suffer from coexisting methodological issues, they currently provide the best possible evidence for developing guidelines on psychosocial first aid. This highlights the importance of searching for study designs that comprise the best available evidence for addressing the research question. Had we limited the search to experimental studies, the guideline would only consist of GPPs based on expert opinion.

When taking a closer look at the personal relationships between communication partners, the results of our systematic literature search showed that receiving positive communication from family members was associated with a reduced risk of developing PTSD or a reduction of PTSD symptom severity in the aftermath of a traumatic event. This finding is in line with other studies, which have suggested that family communication is helpful in 
managing anxiety and posttraumatic symptoms that arise as a direct consequence of traumatic war experiences (Angel et al., 2001) and that individuals usually want to share their experimentally elicited emotions with intimates, such as their parents or close family members, best friends, and/or spouses (Rimé et al., 1992). One can hypothesize that the provision of a safe and comfortable environment is a prerequisite for stimulating effective communication as a mental health intervention and, hence, for reducing the risk of developing PTSD and/or its symptom severity.

It is interesting to note that a study by Zech (1999) suggested that the vast majority of laypeople believe that it is common sense that sharing one's emotion contributes to recovery from a potentially traumatic event. However, the evidence in the present systematic literature search shows that talking about traumatic experiences cannot generally be considered as beneficial for the victim with regard to PTSD development or its symptom severity. Inconclusive evidence has also arisen from several experimental studies investigating emotion-inducing conditions. Whereas Mendolia and Kleck (1993) found that talking about an emotion-inducing film brought physiological recovery, findings reported by Luminet et al. (2000), Rimé et al. (2011), and Zech and Rimé (2005) clearly indicated that talking about an emotion-eliciting condition had no beneficial recovery effect. Whatever the case, it is important to note that individuals talking or writing about upsetting experiences report perceived subjective benefits, such as feeling understood, relieved, or more positive as a result of the experiment (Murray \& Segal, 1994; Zech \& Rimé, 2005). Although paradoxical, the perceived benefits seem to be unrelated to observed recovery outcomes (Zech \& Rimé, 2005). Sharing emotions might not reduce the emotional burden of the experience itself but rather buffer its unsettling effects (Rimé et al., 2011). In addition, most of these laboratory studies were not able to simulate the intensity and severity of past traumatic events and, therefore, were not included in our systematic review; in addition, they often overlooked the importance 
of interpersonal interactions. It remains to be unraveled what factors prove to be beneficial or not with regard to recovery when discussing the traumatic event, taking into account the large heterogeneity in contexts (e.g., accident vs. rape), interventions (e.g., intrapersonal vs. interpersonal communication), and outcomes (e.g., specific recovery from the emotional experience vs. perceived benefits following sharing). Some upsetting events, for example, cannot easily be discussed; in particular, victims of physical and sexual abuse are often reticent to share their feelings or experiences with others due to feelings of guilt or shame (Dahl, 1989; Finkenauer \& Rimé, 1998).

The major limitation of the current analysis was that only data from observational cross-sectional studies were retrieved (i.e., very low certainty of evidence) and, as a consequence, no causal relationships can be inferred from the present results. Although nonspecialist interventions targeting laypeople might be considered as a cost-effective strategy to prevent or reduce posttraumatic symptom severity, there is no high-quality scientific evidence available (Saxena et al., 2007; van Ginneken et al., 2013). To improve the certainty of evidence regarding the effectiveness and validity of early communication provided by laypeople as a first aid intervention following traumatic events, well-conducted experimental studies are needed. These studies will directly reveal whether a strong causal association exists between certain types of communication and the prevention of PTSD development or a reduction of its symptom severity in the aftermath of a traumatic experience. As it is difficult or unethical to perform randomized controlled trials in, for example, disaster-affected populations, observational studies that compare a group of individuals experiencing a specific traumatic event versus an unexposed control group (i.e., cohort-type studies) or studies involving a case group with posttraumatic stress symptomatology versus a control group with no related symptoms (i.e., case-control type studies), whereby both groups are properly matched or weighted based on relevant 
confounding variables, would also provide useful and causal information. Relevant confounding factors are, among others, the victim's previous trauma exposure and history of mental health treatment for PTSD or other mental illnesses. In addition, the present systematic search mainly focused on PTSD-related symptomatology and/or diagnosis as an outcome following a potentially traumatic event. Future efforts should also take other mental health outcomes putatively related to such events into account, such as depression, addiction, or other related disorders. Moreover, the PTSD diagnostic criteria have been subject to several changes since the disorder's introduction 40 years ago, and when assessing the effect sizes, we did not differentiate between the different definitions and outcome measures used. Third, we could not extract a general conclusion from the results due to the substantial heterogeneity between the studies regarding intervention and context.

Finally, this systematic literature search is relevant for practice despite the methodological shortcomings. Practical recommendations could be formulated based on statistical associations inferred from cross-sectional studies when the interpretation of causality was provided by the expert panel. Involving both mental health experts and mental health peer workers-in-training within an expert panel was critical for developing a manual on first aid for mental health problems based on a very low certainty evidence. Based on the limited scientific evidence, expert opinion, and preferences of the target population, one can conclude that offering empathic and supportive communication immediately after a potentially traumatic event as well as in the period thereafter can provide important relief and allow trauma-exposed individuals to better process the traumatic experience.

In conclusion, although a very sensitive search strategy was designed, the present study could not identify any controlled studies concerning the effectiveness of communicative first aid to individuals in mental distress after experiencing a traumatic event. Cross-sectional studies currently provide the most reliable scientific evidence to identify suggestive benefits 
or risks of current psychosocial practices based on statistical associations. We found very limited evidence that positive communication in a family context by the first-aid provider and the expression of feelings by the victim were associated with the victim’s improved mental health status. Based on the best available evidence, we can assume that offering supportive and empathic communication by confidants, such as parents, spouses, or friends, in a safe and comfortable environment is associated with the prevention of PTSD development and a reduction of PTSD symptom severity among trauma-exposed individuals. The identified evidence is scarce and of very low certainty, and the results are imprecise. Hence, we cannot make strong recommendations for practice regarding the hypothesis that communication provided by laypeople is effective in improving posttraumatic mental health. Large highquality studies are warranted to formulate strong, evidence-based recommendations. 


\section{References}

Angel, B., Hjern, A., \& Ingleby, D. (2001). Effects of war and organized violence on children: A study of Bosnian refugees in Sweden. American Journal of Orthopsychiatry, 71(1), 4-15. https://doi.org/10.1037/0002-9432.71.1.4

Arata, C. M. (1999). Coping with rape: The roles of prior sexual abuse and attributions of blame. Journal of Interpersonal Violence, 14(1), 62-78. https://doi.org/10.1177/088626099014001004

Arendt, M., \& Elklit, A. (2001). Effectiveness of psychological debriefing. Acta Psychiatrica Scandinavica, 104(6), 423-437. https://doi.org/10.1034/j.1600-0447.2001.00155.x

American Psychiatric Association. (2013). Diagnostic and statistical manual of mental disorders (5th ed.). Author.

Benjet, C., Bromet, E., Karam, E. G., Kessler, R. C., McLaughlin, K. A., Ruscio, A. M., Shahly, V., Stein, D. J., Petukhova, M., Hill, E., Alonso, J., Atwoli, L., Bunting, B., Bruffaerts, R., Caldas-de-Almeida, J. M., de Girolamo, G., Florescu, S., Gureje, O., Huang, Y,.. . Koenen, K. C. (2016). The epidemiology of traumatic event exposure worldwide: Results from the World Mental Health Survey Consortium. Psychological Medicine, 46(2), 327-343. https://doi.org/10.1017/S0033291715001981

Brewin, C. R., Andrews, B., \& Valentine, J. D. (2000). Meta-analysis of risk factors for posttraumatic stress disorder in trauma-exposed adults. Journal of Consulting and Clinical Psychology, 68(5), 748-766. https://doi.org/10.1037/0022-006X.68.5.748

Bryant, R. A. (2019). Post-traumatic stress disorder: A state-of-the-art review of evidence and challenges. World Psychiatry, 18(3), 259-269. https://doi.org/10.1002/wps.20656

Brymer, M., Taylor, M., Escudero, P., Jacobs, A., Kronenberg, M., Macy, R., Kronenberg, M. Macy, R., Mock, L., Payne, L., Pynoos, R. \& Vogel, J. (2012). Psychological first 
aid for schools: Field operations guide (2nd ed.) National Child Traumatic Stress Network.

Carver, C. S. (2013). COPE Inventory. Measurement instrument database for the social science. http://www.midss.org/content/cope-inventory

Dahl, S. (1989). Acute response to rape-a PTSD variant. Acta Psychiatrica Scandinavica, 80(s355), 56-62. https://doi.org/10.1111/j.1600-0447.1989.tb05254.x

De Buck, E., Pauwels, N. S., Dieltjens, T., \& Vandekerckhove, P. (2014). Use of evidencebased practice in an aid organisation: A proposal to deal with the variety in terminology and methodology. International Journal of Evidence-Based Healthcare, 12(1), 39-49. https://doi.org/10.1097/01.XEB.0000444637.88465.a3

Dieltjens, T., Moonens, I., Van Praet, K., De Buck, E., \& Vandekerckhove, P. (2014). A systematic literature search on psychological first aid: Lack of evidence to develop guidelines. PloS One, 9(12), e114714. https://doi.org/10.1371/journal.pone.0114714

DiMauro, J., \& Renshaw, K. D. (2019). PTSD and relationship satisfaction in female survivors of sexual assault. Psychological Trauma: Theory, Research, Practice, and Policy, 11(5), 534-541. https://doi.org/10.1037/tra0000391

Dockx, K., Stroobants, S., Scheers, H., Borra, V., Brier, N. D., Verlinden, S., Kaesemans, G., De Buck, E., Lauwers, K. \& Vandekerckhove, P. (2020). Providing first aid to individuals experiencing mental health problems: Development of an evidence-based guideline. Manuscript submitted for publication.

Elklit, A. (1997). The aftermath of an industrial disaster. Acta Psychiatrica Scandinavica, 96(s392), 1-25. https://doi.org/10.1111/j.1600-0447.1997.tb05957.x

Finkenauer, C., \& Rimé, B. (1998). Socially shared emotional experiences vs. emotional experiences kept secret: Differential characteristics and consequences. Journal of 
Social and Clinical Psychology, 17(3), 295-318.

https://doi.org/10.1521/jscp.1998.17.3.295

Fox, J. H., Burkle, F. M., Bass, J., Pia, F. A., Epstein, J. L., \& Markenson, D. (2012). The effectiveness of psychological first aid as a disaster intervention tool: Research analysis of peer-reviewed literature from 1990-2010. Disaster Medicine and Public Health Preparedness, 6(3), 247-252. https://doi.org/10.1001/dmp.2012.39

Guyatt, G. H., Oxman, A. D., Vist, G., Kunz, R., Brozek, J., Alonso-Coello, P., Montori, V., Akl, E. A., Djulbegovic, B., Falck-Ytter, Y., Norris, S. L., Williams, J. W., Atkins, D., Meerpohl, J. \& Schünemann, H. J. (2011). GRADE guidelines: 4. Rating the quality of evidence--study limitations (risk of bias). Journal of Clinical Epidemiology, 64(4), 407-415. https://doi.org/10.1016/j.jclinepi.2010.07.017

Guyatt, G. H., Oxman, A. D., Vist, G. E., Kunz, R., Falck-Ytter, Y., Alonso-Coello, P. \& Schünemann, H. J. (2008). GRADE: An emerging consensus on rating quality of evidence and strength of recommendations. BMJ, 336(7650), 924-926. https://doi.org/10.1136/bmj.39489.470347.AD

Kessler, R. C., Aguilar-Gaxiola, S., Alonso, J., Benjet, C., Bromet, E. J., Cardoso, G., Degenhardt, L., de Girolamo, G., Dinolova, R. V. \& Ferry, F. (2017). Trauma and PTSD in the WHO world mental health surveys. European Journal of Psychotraumatology, 8(sup5), 1353383.

https://doi.org/10.1080/20008198.2017.1353383

Khodadadi-Hassankiadeh, N., Dehghan-Nayeri, N., Shahsavari, H., Yousefzadeh-Chabok, S., \& Haghani, H. (2017). Psycho-social and mental variables and post-traumatic stress disorder in traffic accident survivors in northern Iran. Bulletin of Emergency and Trauma, 5(3), 197-205. 
Kitchener, B. A., Jorm, A. F., \& Kelly, C. M. (2015). Mental health first aid international manual. Melbourne: Mental Health First Aid Australia.

Litz, B. T., Gray, M. J., Bryant, R. A., \& Adler, A. B. (2002). Early intervention for trauma: Current status and future directions. Clinical Psychology: Science and Practice, 9(2), 112-134. https://doi.org/10.1093/clipsy.9.2.112

Liu, H., Petukhova, M. V., Sampson, N. A., Aguilar-Gaxiola, S., Alonso, J., Andrade, L. H., Bromet, E J., de Girolamo, G., Haro, J. M., Hinkov, H. Kawakami, N., Koenen, K. C., Kovess-Masfety, V., Lee, S., Medina-Mora, M. E., Navarro-Mateu, F., O’Neill, S., Piazza, M., Posada-Villa, J., . . . Kessler, R. C. (2017). Association of DSM-IV posttraumatic stress disorder with traumatic experience type and history in the World Health Organization World Mental Health Surveys. JAMA Psychiatry, 74(3), 270281. https://doi.org/10.1001/jamapsychiatry.2016.3783

Luminet, O., Bouts, P., Delie, F., Manstead, A. S., \& Rimé, B. (2000). Social sharing of emotion following exposure to a negatively valenced situation. Cognition \& Emotion, 14(5), 661-688. https://doi.org/10.1080/02699930050117666

Machisa, M. T., Christofides, N., \& Jewkes, R. (2018). Social support factors associated with psychological resilience among women survivors of intimate partner violence in Gauteng, South Africa. Global Health Action, 11(3), 1491114. https://doi.org/10.1080/16549716.2018.1491114

McNally, R. J., Bryant, R. A., \& Ehlers, A. (2003). Does early psychological intervention promote recovery from posttraumatic stress? Psychological Science in the Public Interest, 4(2), 45-79. https://doi.org/10.1111/1529-1006.01421

Mendolia, M. \& Kleck, R. E. (1993). Effects of talking about a stressful event on arousal: does what we talk about make a difference? Jourbal of Personality and Social Psychology, 64(2), 283-292. https://doi.org/10.1037/0022-3514.64.2.283 
Milot, T., St-Laurent, D., Éthier, L. S., \& Provost, M. A. (2010). Trauma-related symptoms in neglected preschoolers and affective quality of mother-child communication. Child Maltreatment, 15(4), 293-304. https://doi.org/10.1177/1077559510379153

Moher, D., Liberati, A., Tetzlaff, J., \& Altman, D. G. (2009). Preferred reporting items for systematic reviews and meta-analyses: The PRISMA statement. PLoS Medicine, 6(6), e1000097. https://doi.org/10.1371/journal.pmed.1000097

Morgan, A. J., Ross, A., \& Reavley, N. J. (2018). Systematic review and meta-analysis of Mental Health First Aid training: Effects on knowledge, stigma, and helping behaviour. PloS One, 13(5), e0197102.

Murray, E. J., \& Segal, D. L. (1994). Emotional processing in vocal and written expression of feelings about traumatic experiences. Journal of Traumatic Stress, 7(3), 391-405. https://doi.org/10.1002/jts.2490070305

Navia, C., \& Ossa, M. (2003). Family functioning, coping, and psychological adjustment in victims and their families following kidnapping. Journal of Traumatic Stress, 16(1), 107-112. https://doi.org/10.1023/A:1022023730711

Njenga, F. G., Nicholls, P. J., Nyamai, C., Kigamwa, P., \& Davidson, J. R. T. (2004). Posttraumatic stress after terrorist attack: Psychological reactions following the U.S. embassy bombing in Nairobi-Naturalistic study. British Journal of Psychiatry, 185(4), 328-333. https://doi.org/10.1192/bjp.185.4.328

Rimé, B., Paez, D., Kanyangara, P., \& Yzerbyt, V. (2011). The social sharing of emotions in interpersonal and in collective situations: Common psychosocial consequences. In I. Nyklicek, A. Vingerhoets, \& M. Zeelenberg (Eds.), Emotion regulation and wellbeing (pp. 147-163). Springer. 
Rimé, B., Philippot, P., Boca, S., \& Mesquita, B. (1992). Long-lasting cognitive and social consequences of emotion: Social sharing and rumination. European Review of Social Psychology, 3(1), 225-258. https://doi.org/10.1080/14792779243000078

Rose, S., Bisson, J., Churchill, R., \& Wessely, S. (2002). Psychological debriefing for preventing post traumatic stress disorder (PTSD). Cochrane Database of Systematic Reviews, 2, CD000560. https://doi.org/10.1002/14651858.CD000560

Rose, S., Bisson, J., \& Wessely, S. (2003). A systematic review of single-session psychological interventions ("debriefing") following trauma. Psychotherapy and Psychosomatics, 72(4), 176-184. https://doi.org/10.1159/000070781

Saxena, S., Thornicroft, G., Knapp, M., \& Whiteford, H. (2007). Resources for mental health: Scarcity, inequity, and inefficiency. The Lancet, 370(9590), 878-889. https://doi.org/10.1016/S0140-6736(07)61239-2

Schafer, A., Snider, L., \& van Ommeren, M. (2010). Psychological first aid pilot: Haiti emergency response. Intervention, 8(3), 245-254. https://doi.org/10.1097/WTF.0b013e32834134cb

Tucker, P., Pfefferbaum, B., Nixon, S., \& Dickson, W. (2000). Predictors of post-traumatic stress symptoms in Oklahoma city: Exposure, social support, peri-traumatic responses. The Journal of Behavioral Health Services \& Research, 27(4), 406-416. https://doi.org/10.1007/BF02287822

Van Emmerik, A. A., Kamphuis, J. H., Hulsbosch, A. M., \& Emmelkamp, P. M. (2002). Single session debriefing after psychological trauma: A meta-analysis. The Lancet, 360(9335), 766-771. https://doi.org/10.1016/S0140-6736(02)09897-5

van Ginneken, N., Tharyan, P., Lewin, S., Rao, G. N., Meera, S. M., Pian, J., Chandrashekar, S. \& Patel, V. (2013). Non-specialist health worker interventions for the care of mental, neurological, and substance-abuse disorders in low- and middle-income 
countries. Cochrane Database of Systematic Reviews, 11, CD009149. https://doi.org/10.1002/14651858.CD009149.pub2

World Health Organization, War Trauma Foundation, and World Vision International (2011). Psychological first aid: Guide for field workers. World Health Organization.

Yehuda, R., \& LeDoux, J. (2007). Response variation following trauma: A translational neuroscience approach to understanding PTSD. Neuron, 56(1), 19-32. https://doi.org/10.1016/j.neuron.2007.09.006

Zech, E. (1999). Is it really helpful to verbalise one’s emotions? Gedrag \& Gezondheid, 27(1-2), 42-47.

Zech, E., \& Rimé, B. (2005). Is talking about an emotional experience helpful? Effects on emotional recovery and perceived benefits. Clinical Psychology \& Psychotherapy: An International Journal of Theory \& Practice, 12(4), 270-287. https://doi.org/10.1002/cpp.460 


\section{Table 1}

Characteristics of the Included Studies

\begin{tabular}{|c|c|c|c|c|c|}
\hline $\begin{array}{l}\text { First author, } \\
\text { year }\end{array}$ & Country & $\begin{array}{l}\text { Study } \\
\text { design }\end{array}$ & Population & Risk factor & Outcome measures \\
\hline Arata, 1999 & $\begin{array}{l}\text { United } \\
\text { States }\end{array}$ & $\begin{array}{l}\text { Cross- } \\
\text { section } \\
\text { al study }\end{array}$ & $\begin{array}{l}119 \text { female students ( } M_{\text {age }}=23 \text { years) } \\
\text { who experienced forced sex acts, out } \\
\text { of } 860 \text { female students who were } \\
\text { recruited from introductory } \\
\text { psychology classes (i.e., } 14 \% \text { of total) }\end{array}$ & $\begin{array}{l}\text { Expressive coping factor } \\
\text { (expressing feelings around } \\
\text { others and talking about your } \\
\text { feelings to others): How I Deal } \\
\text { with Things scale }\end{array}$ & $\begin{array}{l}\text { PTSD and other } \\
\text { posttrauma symptom } \\
\text { severity: TSC-33 }\end{array}$ \\
\hline $\begin{array}{l}\text { DiMauro, } \\
2019\end{array}$ & $\begin{array}{l}\text { United } \\
\text { States }\end{array}$ & $\begin{array}{l}\text { Cross- } \\
\text { section } \\
\text { al study }\end{array}$ & $\begin{array}{l}164 \text { female victims of sexual assault } \\
\left(M_{\text {age }}=28.5 \text { years, average time since }\right. \\
\text { assault }=6.3 \text { years })\end{array}$ & $\begin{array}{l}\text { Negative and positive } \\
\text { communication: CPQ-SF }\end{array}$ & $\begin{array}{l}\text { PTSD symptom } \\
\text { severity: PCL-5 }\end{array}$ \\
\hline Elklit, 1997 & Denmark & $\begin{array}{l}\text { cross- } \\
\text { section } \\
\text { al study }\end{array}$ & $\begin{array}{l}270 \text { workers ( } 257 \text { men, } 12 \text { women, } \\
\text { one unknown gender; } M_{\mathrm{age}}=42.3 \\
\text { years), } 6 \text { months after exposure to an } \\
\text { explosion on a supertanker. }\end{array}$ & $\begin{array}{l}\text { Social-emotional coping } \\
\text { (i.e.,COPE Items 11, 23, 34, } \\
\text { 52; Carver, 2013) }\end{array}$ & $\begin{array}{l}\text { PTSD symptom } \\
\text { severity: IES }\end{array}$ \\
\hline
\end{tabular}




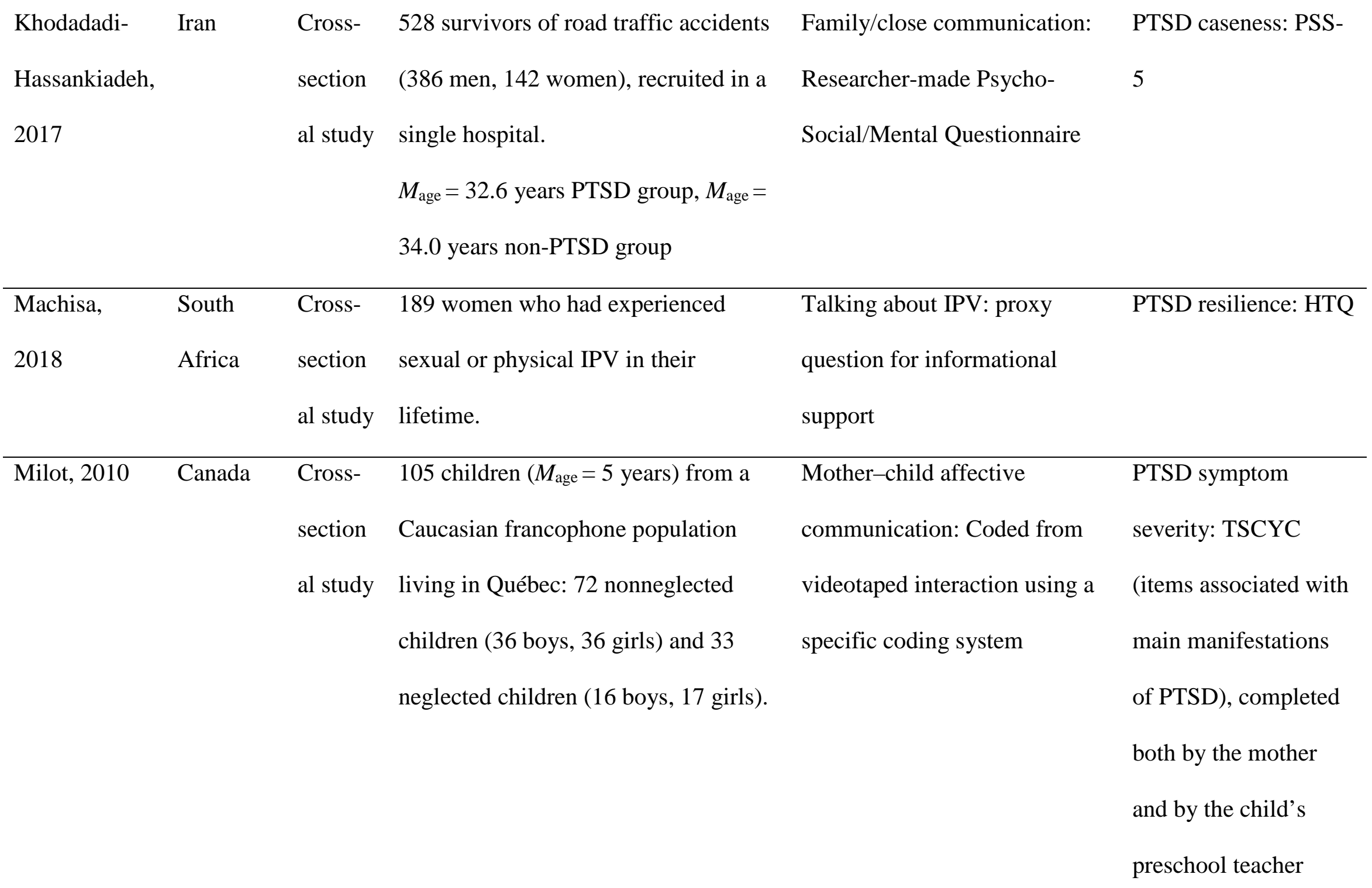




\begin{tabular}{|c|c|c|c|c|c|}
\hline Navia, 2003 & Colombia & $\begin{array}{l}\text { Cross- } \\
\text { section } \\
\text { al study }\end{array}$ & $\begin{array}{l}72 \text { families of economic extortive } \\
\text { kidnapping:18 living the captivity of } \\
\text { one of its members, } 54 \text { grouped } \\
\text { according to time after release (i.e., 2- } \\
\text { 4, 5-8, and 9-15 months). } \\
213 \text { total individuals ( } 113 \text { women, } 100 \\
\text { men, } M_{\text {age }}=38 \text { years): } \\
55 \text { kidnapped individuals who had } \\
\text { been released, } 158 \text { family members. }\end{array}$ & Communication: FAD & $\begin{array}{l}\text { PTSD symptom } \\
\text { severity: CAPS-DX }\end{array}$ \\
\hline & & $\begin{array}{l}\text { section } \\
\text { al study }\end{array}$ & $\begin{array}{l}\text { women; } M_{\text {age }}=33.6 \text { years) recruited } \\
1-3 \text { months after a terrorist attack. }\end{array}$ & $\begin{array}{l}\text { attack with a friend/workmate, } \\
\text { family member, or another } \\
\text { individual (religious leader, } \\
\text { counselor, psychologist): Six } \\
\text { questions about attack-related } \\
\text { conversation and counseling }\end{array}$ & $\begin{array}{l}\text { yes/no questions and } \\
\text { an algorithm based on } \\
D S M-I V \text { Clusters B, } \\
\text { C, and D }\end{array}$ \\
\hline
\end{tabular}




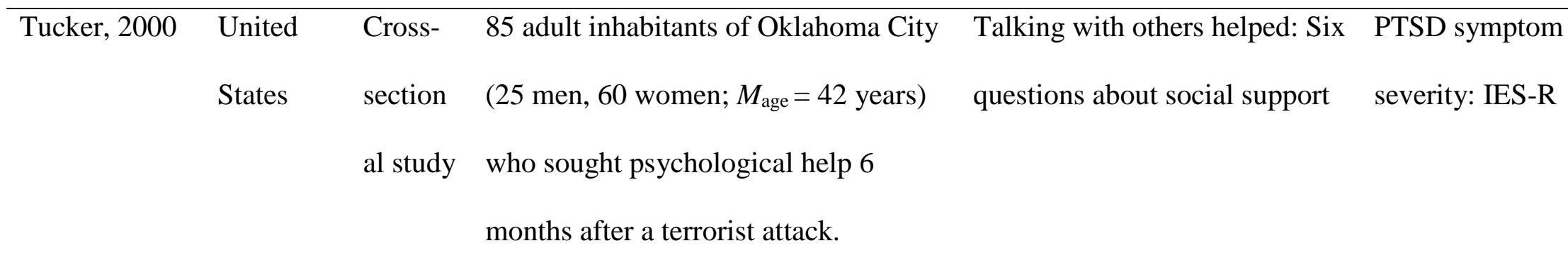

Note.; PTSD = posttraumatic stress disorder; TSC-33 = 33-item Trauma Symptom Checklist; PCL-5 = PTSD Checklist for DSM-5; IES = Impact of Events Scale; CPQ-SF = Short-Form Communication Patterns Questionnaire; PSS-5 = Posttraumatic Stress Scale for DSM-5; IPV = intimate partner violence; HTQ = Harvard Trauma Questionnaire; TSCYC = Trauma Symptom Checklist for Young Children.; FAD = Family Assessment Device; CAPS-DX = Clinician-Administered PTSD Scale-Diagnostic Version for DSM-IV; IES-R = IES-Revised. 


\section{Table 2}

Synthesis of Findings

\begin{tabular}{|c|c|c|c|c|c|c|}
\hline \multirow{3}{*}{ Risk factor } & \multicolumn{4}{|c|}{ Effect size } & \multirow{3}{*}{ Participants } & \multirow{3}{*}{$\begin{array}{c}\text { First } \\
\text { author, } \\
\text { year }\end{array}$} \\
\hline & \multirow[b]{2}{*}{$r$} & \multicolumn{2}{|l|}{ Estimate } & \multirow[t]{2}{*}{$95 \% \mathrm{CI}$} & & \\
\hline & & $\mathrm{aOR}$ & $\beta$ & & & \\
\hline \multicolumn{7}{|c|}{ Communication in general } \\
\hline \multicolumn{7}{|l|}{ PTSD symptom severity or } \\
\hline Negative communication & $.28 * *$ & & & - & & DiMauro, \\
\hline Positive communication & $-.38 * * *$ & & & - & 164 & 2019 \\
\hline Family communication & & $0.26 * *$ & & {$[0.09,0.75]$} & 528 & $\begin{array}{l}\text { Khodadad } \\
\text { i- } \\
\text { Hassankia } \\
\text { deh, } 2017\end{array}$ \\
\hline Mother-child & & & $-.22 *$ & {$[-.41,-.04]$} & 103 & Milot, \\
\hline communication & & & & & & 2010 \\
\hline Communication during & .31 & & & - & 18 & \\
\hline captivity & & & & & & Navia, \\
\hline $\begin{array}{l}\text { Communication after } \\
\text { release }\end{array}$ & .20 & & & - & 54 & 2003 \\
\hline
\end{tabular}


PTSD resilience

Talking to someone

$[0.59,2.80]$

Machisa,

else about IPV

189

2018

PTSD symptom severity or

caseness

Talking about the

attack, but not to a

- ** -

2627

Njenga,

friend/co-worker

2004

Talking with others

$-.15$

85

Tucker,

helped

$-$

2000

\section{Communication-based coping strategies}

PTSD (and other

posttrauma) symptom

severity

Expressive coping

$-.62 * * * \quad[-.94,-.31]^{\mathrm{a}}$

112

Arata,

1999

Social-emotional

$.50 * *$

270

Elklit,

coping

1997

Note. “_“ indicates an effect size estimate was not available or confidence intervals could not be

calculated. aOR = adjusted odds ratio; PTSD = posttraumatic stress disorder; IPV = intimate

partner violence

${ }^{*} \mathrm{p}<.05, * * \mathrm{p}<.01$, and $* * * \mathrm{p}<.001$ 
${ }^{a}$ Calculations completed using Review Manager (Version 5.3). 


\section{Figure 1}

PRISMA Flowchart for the Selection of Eligible Studies

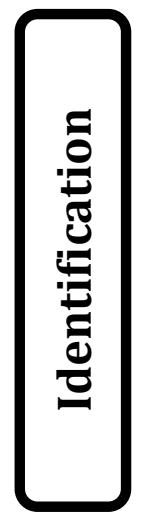

Records identified through database searching

$$
N=2,370
$$

PsycINFO: $n=590$

MEDLINE: $n=789$

Embase: $n=991$

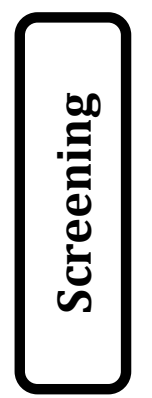

Records after duplicates removed

$$
n=1,724
$$

\section{Duplicates removed}

$$
n=646
$$

Records excluded based on title and abstract

$n=1,493$

\section{Full-text articles assessed for eligibility}

$$
n=231
$$

\section{3 full-text articles excluded}

- Intervention: $n=190$

- Study design: $n=17$

- Other: $n=10$

- Population: $n=3$

- Language: $n=2$

- Outcome: $n=1$

Full-text articles included after reference list and similar article search: $n=1$

\section{Studies included}

$$
N=9
$$

